\title{
Potential of sugi wood diterpenes as an Alzheimer's disease preventive and therapeutic drug by the $\beta$-amyloid toxicity reduction effect
}

\author{
Yoshie Yamaji ${ }^{1}$, Tokumitsu Wakabayashi ${ }^{2}$ and Hisayoshi Kofujita ${ }^{1 *}$ (i)
}

Part of this report was presented at the 68th Annual Meeting of the Japan Wood Research Society, Kyoto, Japan, March 2018

\begin{abstract}
Alzheimer's disease is the most common form of dementia, and neurological disorder from beta amyloid (Aß) peptide is regarded as a cause of Alzheimer's disease. In this study, the authors evaluate A $\beta$ toxicity reduction effects of major diterpenes isolated from sugi wood by bioassay using Caenorhabditis elegans and examined its relationship with the antioxidative activity. Among the six kinds of sugi wood diterpenes: ferruginol, 6,7-dehydroferruginol, sandaracopimarinal, sandaracopimarinol, abietadiene, abietatriene and phyllocladenes, prominent A $\beta$ toxicity reduction effects were found in ferruginol and 6,7-dehydroferruginol, and their activity was almost equivalent to that of the four kinds of anti-Alzheimer active agents that have been reported so far: ginkgolide A, morin, rosmarinic acid and carnosic acid. Antioxidative activity similar to other anti-Alzheimer active agents was found in ferruginol and 6,7-dehydroferruginol in a 1,1-Diphenyl-2-picrylhydrazyl (DPPH) radical scavenging activity test, which suggested that antioxidative activity is concerned with expression of the $A \beta$ toxicity reduction effect of sugi wood diterpenes.
\end{abstract}

Keywords: Cryptomeria japonica, Terpenoids, Alzheimer's disease

\section{Introduction}

The aging rate in Japan reached $28.1 \%$ in 2019 (the rate of population of 65 years or older among the entire population) and a super-aging society that is unprecedented anywhere around the globe is coming [1]. Dementia is one of the most serious social problems accompanied with aging, and the number of patients in 2025 is estimated to be over 7 million. Among them, the number of Alzheimer's disease patients is estimated to be $4,660,000$, and it is predicted that the majority of future dementia

\footnotetext{
${ }^{*}$ Correspondence: kofujita@iwate-u.ac.jp

${ }^{1}$ Faculty of Agriculture, Iwate University, Ueda 3-18-8, Morioka, I wate 020-8550, Japan

Full list of author information is available at the end of the article
}

patients will suffer from Alzheimer's disease [2]. Beta amyloid $(A \beta)$ is said to be the etiology of Alzheimer's disease, which is supported by many evidences (amyloid hypothesis), but the pathology and mechanism of Alzheimer's disease remain unclear [3].

$\mathrm{A} \beta$ is a peptide that is constantly biosynthesized as a metabolite, and several types that have 36-43 amino acid residues are known. Highly agglutinative $A \beta 42$ is particularly produced excessively in an Alzheimer's disease patient's brain, and aggregates called senile plaque are formed in the brain of a patient with serious symptoms [4]. Based on the above-mentioned findings, treatment strategies that targeted $A \beta 42$ and its aggregates have been focused. $A \beta 42$ polymerizes with radical formation reaction by oxidation of tyrosine, which is a constituent 
amino acid, as a starting point, and expresses neuronal cell toxicity during the process in which it aggregates and deposits [5]. Furthermore, it has been reported that the reactive oxygen species concentration in tissues rises by polymerization of $A \beta$ and that increased oxidation stress caused by polymerized $A \beta$ is deeply involved with the expression of neurotoxicity [6].

The authors isolated and identified several kinds of diterpene from volatile compounds discharged from the sugi wood-drying process and reported that some of these have prominent antioxidative effects [7]. In this study, the authors evaluated the $A \beta$ toxicity reduction effect of major diterpenes isolated from sugi wood by bioassay using Caenorhabditis elegans and moreover examined their relationship with the antioxidative activity.

\section{Materials and methods}

\section{Samples and reagents}

Sugi wood (Cryptomeria japonica) diterpene (Fig. 1): ferruginol (I), 6,7-dehydroferruginol (II), sandaracopimarinal (III), sandaracopimarinol (IV), abietadiene (V), abietatriene (VI) and phyllocladenes (VII-i and -ii; mixture of phyllocladene and isophyllocladene) were isolated and identified according to a previous report [7]. The chemical structure and purity of each compound were confirmed by Gas chromatography (GC) and ${ }^{1} \mathrm{H} /{ }^{13} \mathrm{C}$ Nuclear magnetic resonance (NMR). The isolated diterpenoids are more than 95\% pure. Ginkgolide A was purchased from Funakoshi Co.; rosmarinic acid was purchased from SIGMA-ALDRICH; carnosic acid and 1,1-Diphenyl-2-picrylhydrazyl (DPPH) were purchased from Tokyo Chemical Industry Co., Ltd. and morin and 2,6-Di-tert-butyl-4-methylphenol (BHT) were purchased from Fujifilm Wako Pure Chemical Corporation. These purchased compounds and reagents are also more than 95\% pure.

\section{Caenorhabditis elegans and management}

C.elegans CL4176 strains were provided by Caenorhabditis Genetics Center (University of Minnesota, Minneapolis, MN) (Fig. 2). A $\beta$ synthetic gene with the temperature dependency is incorporated in CL4176 strain, toxic $A \beta 1-42$ is expressed in a muscle tissue-specific manner by raising breeding temperature from 16 to $25^{\circ} \mathrm{C}$ and it becomes the paralysis [8]. The C.elegans were bred and preserved on a Nematode Growth Medium (NGM) storage plate at $16{ }^{\circ} \mathrm{C}$ with Escherichia coli OP50

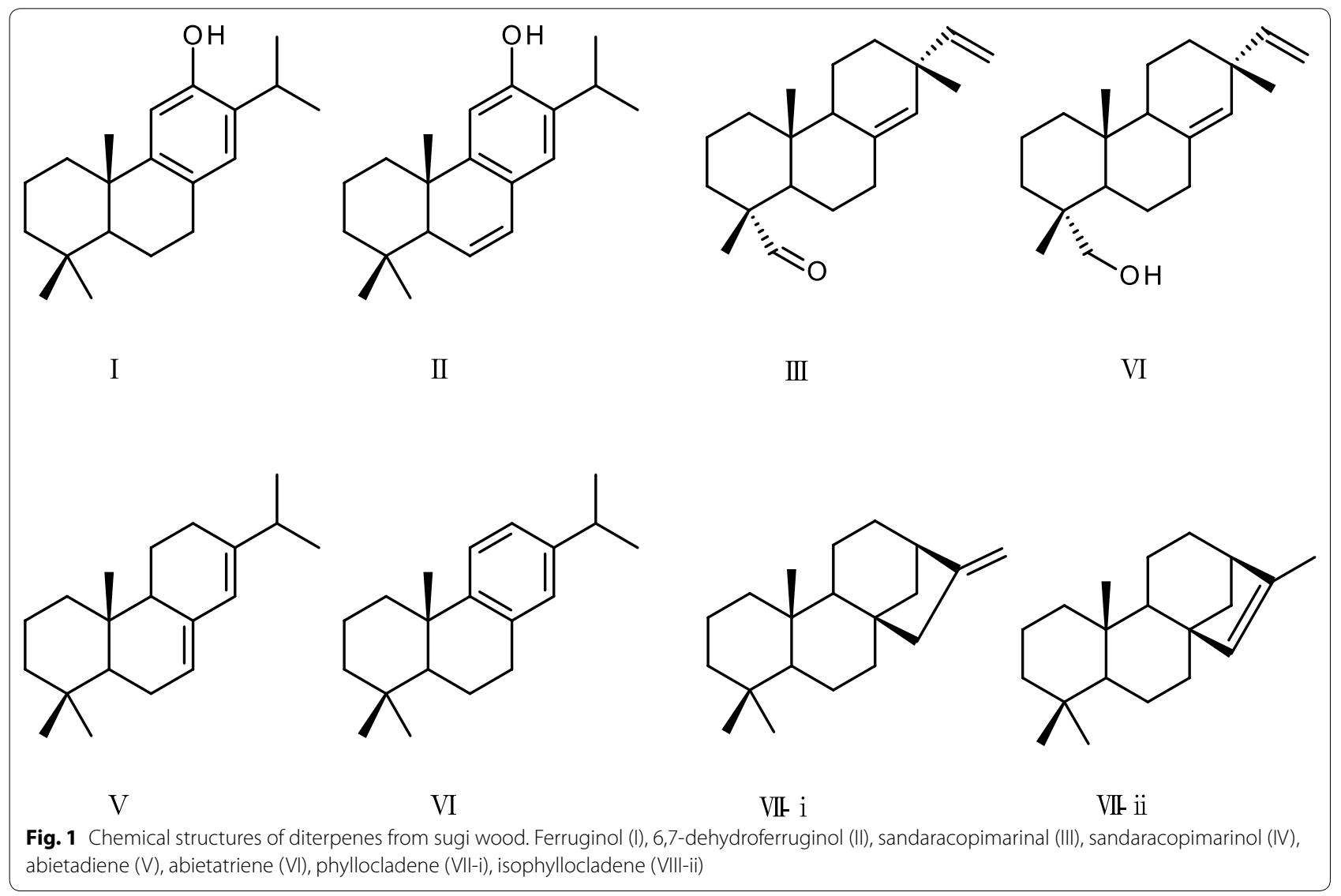




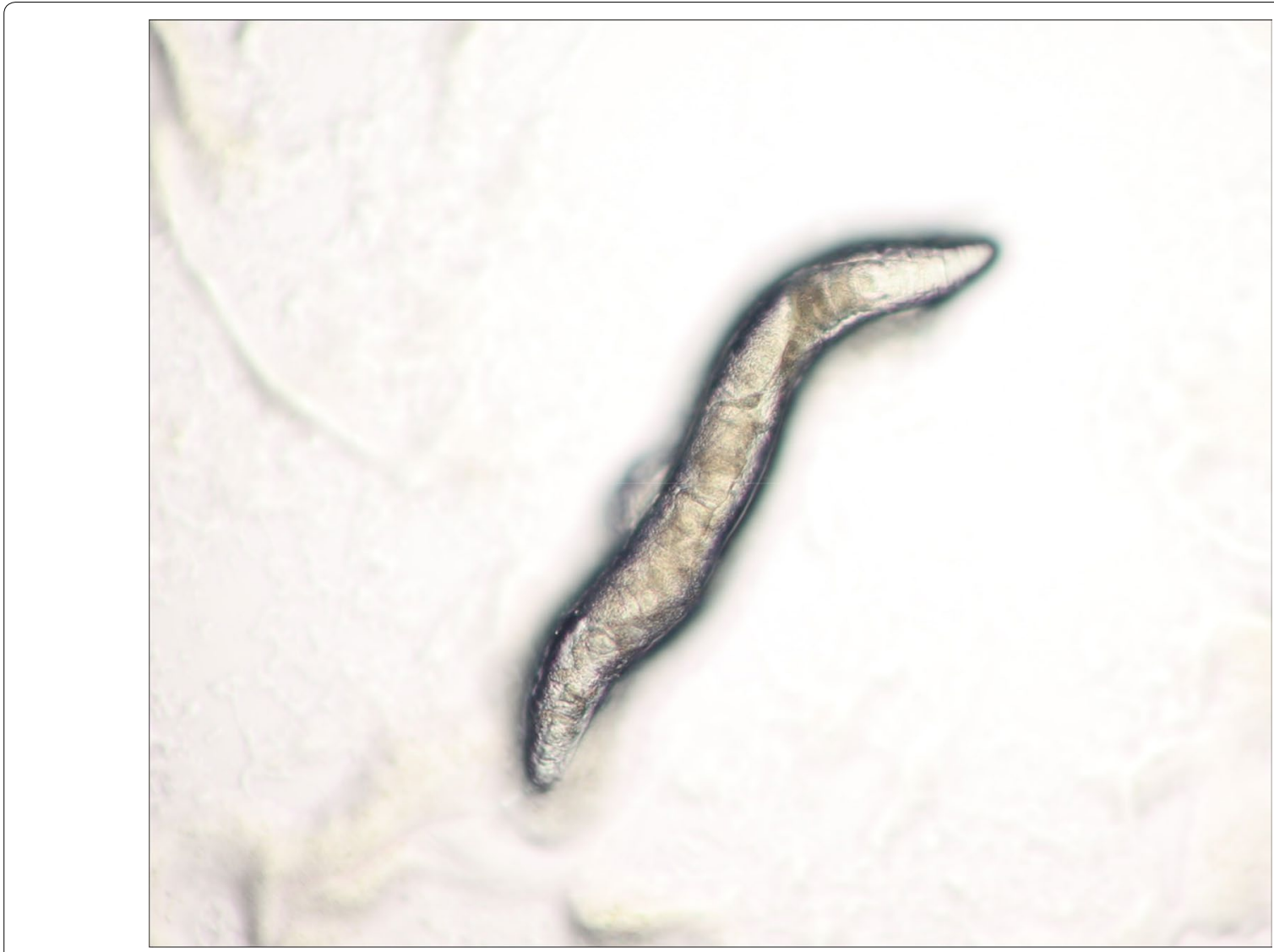

Fig. 2 Caenorhabditis elegans CL4176

as feed, and moved to new storage plates once in 4 days. $E$. coli OP50 that was inoculated into $8 \mathrm{~mL}$ of LuriaBertani (LB) media and cultured at $25^{\circ} \mathrm{C}$ overnight was used as bacterial cell suspension according to the usual manner. For the storage plate for C. elegans, $10 \mu \mathrm{L}$ of $E$. coli OP50 suspension was dropped onto an NGM plate, spread with a spreader and cultured at $25{ }^{\circ} \mathrm{C}$ for one night before use.

\section{$A \beta$ toxicity reduction test (C. elegans paralysis test)} Preparation of a test plate, $10 \mu \mathrm{L}$ of $E$. coli OP50 suspension and $10 \mu \mathrm{L}$ of sample solution $(0.5 \mathrm{mg} / \mathrm{mL}$ dimethyl sulfoxide solution, as molarity of I:1.7 $\mu \mathrm{M}$, II:1.8 $\mu \mathrm{M}$, III:1.8 $\mu \mathrm{M}, \mathrm{IV}: 1.7 \mu \mathrm{M}, \mathrm{V}: 1.8 \mu \mathrm{M}, \mathrm{VI}: 1.8 \mu \mathrm{M}$, VII:1.8 $\mu \mathrm{M}$, ginkgolide A:1.2 $\mu \mathrm{M}$, rosmarinic acid:1.4 $\mu \mathrm{M}$, carnosic acid:1.5 $\mu \mathrm{M}$, morin:1.7 $\mu \mathrm{M}$ ) were dropped onto an NGM plate, and spread with a spreader. Only DMSO was used for a control plate instead of the sample solution. Twenty five L3 larvae of synchronized C. elegans CL4176 that was grown at $16{ }^{\circ} \mathrm{C}$ were taken to each of two plates and moved to an incubator of $25{ }^{\circ} \mathrm{C}$ to have A $\beta$ genes expressed. Observation was started $20 \mathrm{~h}$ after raising temperature to $25^{\circ} \mathrm{C}$ and the number of paralyzed individuals was counted every two hours. $A \beta$ toxicity reduction effects of each sample were assessed by statistically analyzing data obtained from the test plate and control plate using the Kaplan-Meier method (log-rank test).

\section{Radical scavenging activity test}

DPPH was dissolved in ethanol at the concentration of $0.2 \mathrm{mM}$. Each diterpenoid sample was dissolved in ethanol at a concentration of $10 \mathrm{mM}$. BHT was used as a positive control. First, $0.2 \mathrm{~mL}$ of sample solution, $1.0 \mathrm{~mL}$ of DPPH solution, $0.2 \mathrm{~mL}$ of $0.1 \mathrm{M}$ Tris-HCL ( $\mathrm{pH}$ 7.4) buffer, and $0.6 \mathrm{~mL}$ of ethanol were mixed in a screw tube. Then, the screw tubes were shaken, and allowed to react at room temperature under dark conditions. After $30 \mathrm{~min}$, the absorbance was measured at $517 \mathrm{~nm}$ by UV mini 1240 (SHIMADZU, Japan). Based on the data obtained by each concentration, concentration for $50 \%$ inhibition concentration (IC50) was calculated.

\section{GC}

GC was performed on a 7890B GC System (Agilent Technologies, Santa Clara, CA, USA) equipped with an HP-5 column $(30 \mathrm{~m} \times 0.25 \mathrm{~mm}$ i.d., $0.25 \mu \mathrm{m}$ film thickness, 
Agilent Technologies). The oven temperature started at $60{ }^{\circ} \mathrm{C}$ and increased at $3.0^{\circ} \mathrm{C} / \mathrm{min}$ to at $240{ }^{\circ} \mathrm{C}$. The injector and the detector temperatures were both $250^{\circ} \mathrm{C}$.

\section{NMR}

NMR spectra $\left({ }^{1} \mathrm{H}: 400 \mathrm{MHz},{ }^{13} \mathrm{C}: 100 \mathrm{MHz}\right)$ were recorded on a JEOL AL400 FT-NMR spectrometer. Each purified diterpenoid $(50 \mathrm{mg}$ ) was dissolved in $0.7 \mathrm{~mL}$ chloroform- $d$. The experimentally measured spectra were compared with data from the previous report [7].

\section{Results and discussion}

To examine the $A \beta$ toxicity reduction effect of sugi wood diterpenes, each diterpenoid at the final concentration of $0.5 \mathrm{mg} / \mathrm{mL}$ was given to C. elegans and paralysis rates were observed (Fig. 3). As a result of examining the difference in non-paralysis rates, significantly positive effects were found in the experimental plot of ferruginol and 6,7 -dehydroferruginol $(p<0.05)$. These results indicated that expression of paralysis from $\mathrm{A} \beta$ toxicity in C.elegans
CL4176 was suppressed by administering ferruginol and 6,7-dehydroferruginol. On the other hand, significant differences were not found in experimental plots of other sugi wood diterpenes, and it has been revealed that the $A \beta$ toxicity reduction effect is a property peculiar to ferruginol and related compounds. This study reports the anti-Alzheimer's disease effects from extracts of sugi wood for the first time.

As for the anti-Alzheimer's disease activity of extractives from plants, the effects of natural compounds such as ginkgolide A [9], morin [10], rosmarinic acid [11] and carnosic acid [12] have been reported. In this study, to examine how the $A \beta$ toxicity reduction effect of ferruginol is effective in comparison with the above anti-Alzheimer active compounds, a simultaneous comparison in the C. elegans CL4176 paralysis test was performed with commercial reagents of each active compound as a positive control. As a result of examining the difference in non-paralysis rates, significant differences were not found between the positive control-added plate
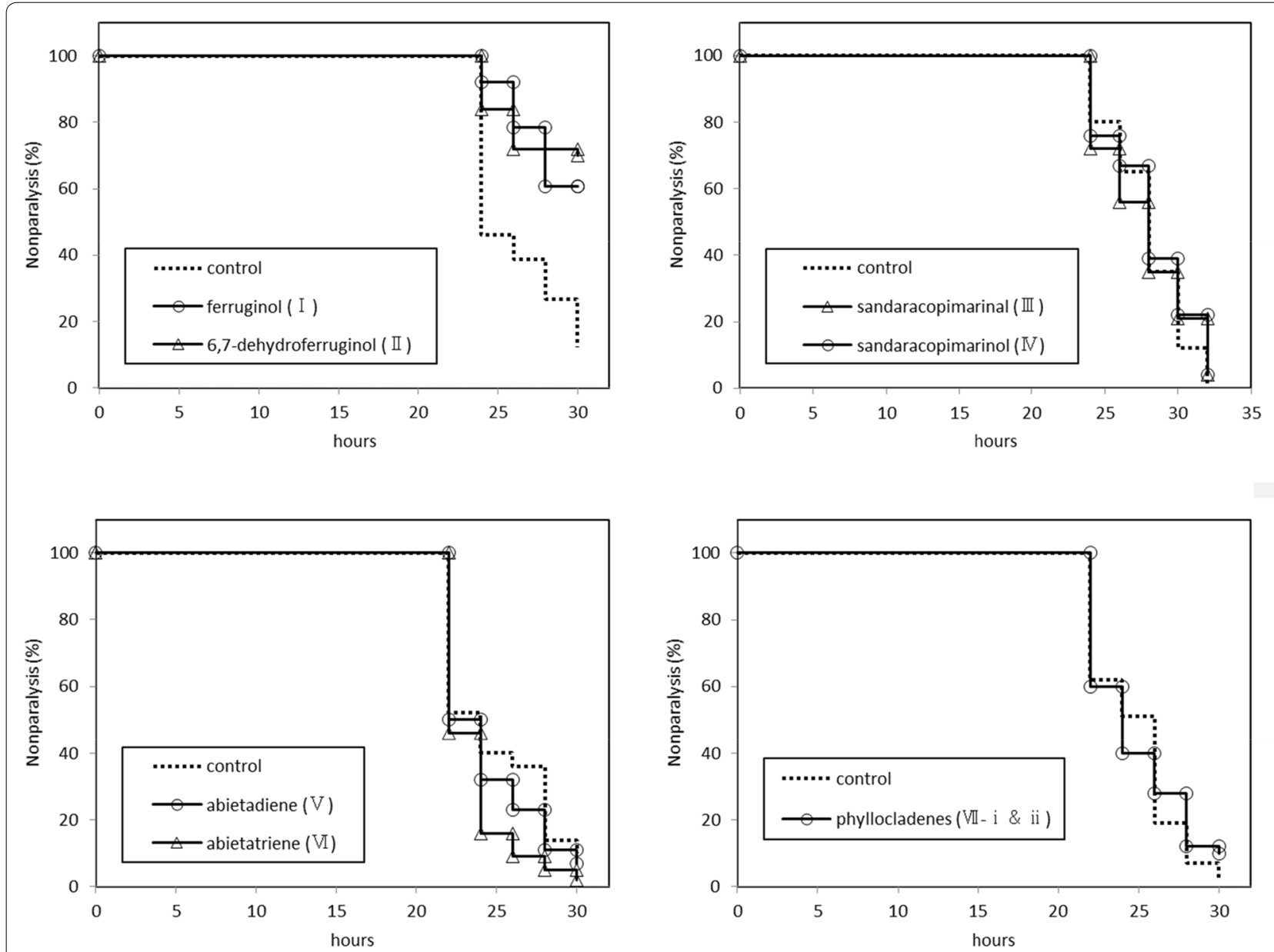

Fig. 3 Time course of paralysis assays in C.elegans CL4176 fed with sugi wood diterpenes 
and ferruginol-added plate in either experiment system (Fig. 4). These results suggest that ferruginol has antiAlzheimer's disease effects that are equal to other natural active agents reported in the previous studies.

The onset of Alzheimer's disease is presumably associated with enhancement of oxidation stress in a brain [13]. In this study, to examine the relationship between $A \beta$ toxicity reduction effect and the antioxidative activity of sugi wood terpenoid, the DPPH radical scavenging activity of major sugi wood diterpenes was measured. Six kinds of purified diterpenes, four kinds of anti-Alzheimer's disease active compounds and BHT (positive control), which is a commercial anti-oxidant, were used for samples and 50\% inhibition concentration (IC50) was calculated (Table 1). Among the sugi wood diterpenes used for the experiment, the only two compounds that presented prominent activity were ferruginol and 6,7-dehydroferruginol (IC50 $=7.2 \mathrm{mM}$ and $0.9 \mathrm{mM}$, respectively), and antioxidative activity was not found in
Table 1 IC50 of sugi wood diterpenes and reference compounds in DPPH radical scavenging activity

\begin{tabular}{llll}
\hline $\begin{array}{l}\text { Sugi wood } \\
\text { diterpenes }\end{array}$ & IC50 (mM) & $\begin{array}{l}\text { Reference } \\
\text { compounds }\end{array}$ & IC50 (mM) \\
\hline BHT (positive control) & 1.47 & Ginkgolide A & n.d \\
$\begin{array}{l}\text { Ferruginol (I) } \\
\begin{array}{l}\text { 6,7-Dehydroferrugi- } \\
\text { nol (II) }\end{array}\end{array}$ & 0.90 & Carnosic acid & 0.50 \\
$\begin{array}{l}\text { Other diterpenes } \\
\text { (III, IV, V, VI, VII-i and -ii) }\end{array}$ & n.d & Morin & 0.03 \\
\hline
\end{tabular}

high concentration of $10 \mathrm{mM}$ for other diterpenes. $\mathrm{A} \beta$ toxicity reduction effect and antioxidative activity were found in ferruginol and 6,7-dehydroferruginol, while no activities were found in the other sugi wood diterpenes, and antioxidative activity was found in the three kinds of positive controls. These findings suggest the relationships
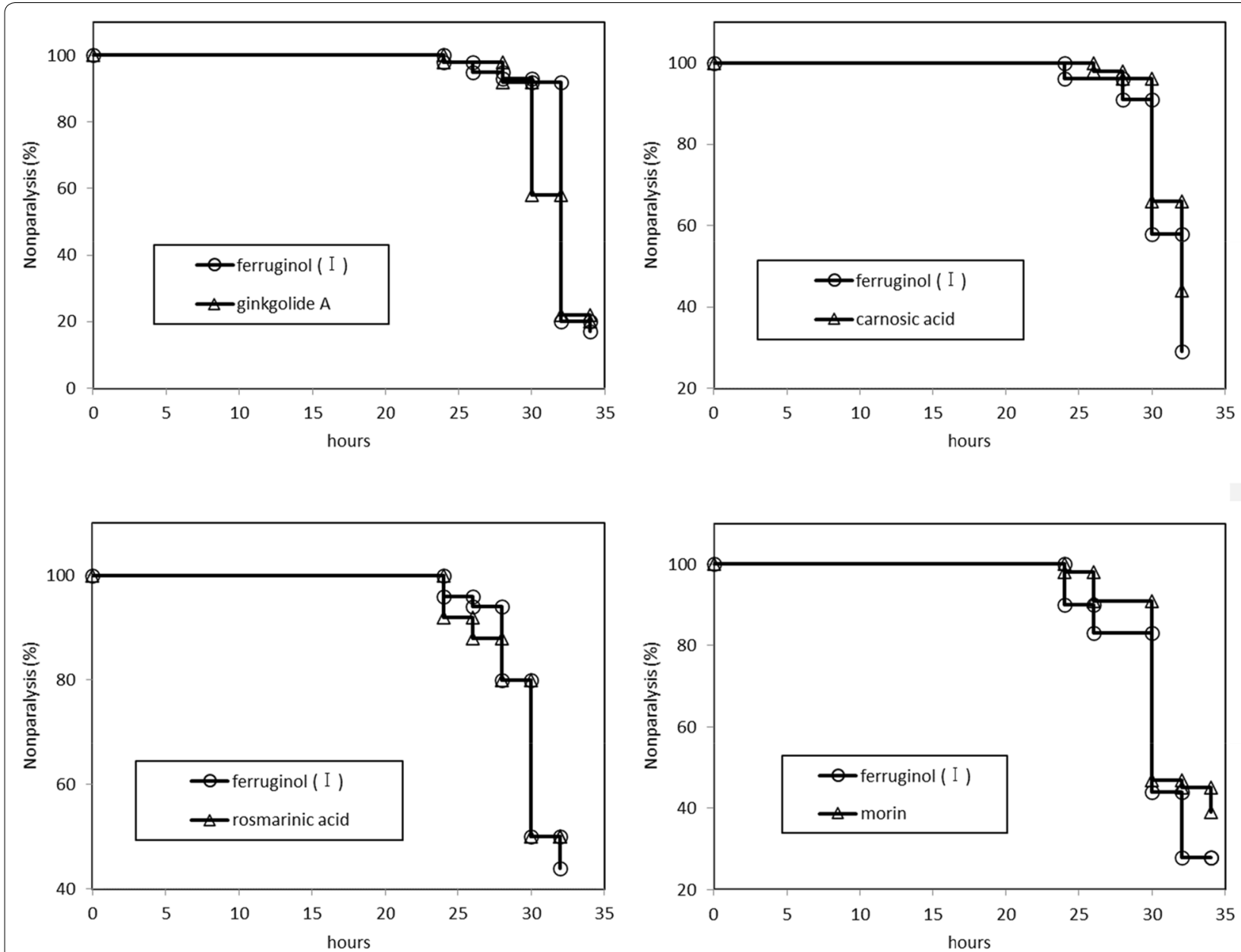

Fig. 4 Time course of paralysis assays in C.elegans CL4176 fed with ferruginol and reference compounds (anti-Alzheimer's disease active compounds) 
between $A \beta$ toxicity reduction effect of ferruginol/6,7dehydroferruginol and antioxidative activity.

As the mechanism of antioxidative reaction by ferruginol, the process that the radical of the object substance is removed by ferruginol being oxidized to sugiol through quinone methide intermediates has been proposed [14]. The results obtained in this study suggest that ferruginol suppresses $A \beta$ polymerization and oxidation stress by scavenging $A \beta$ radical based on a similar mechanism. It is necessary to clarify the reaction mechanism of $A \beta$ toxicity reduction effect by ferruginol in detail.

\section{Conclusions}

The two kinds of diterpenes, ferruginol and 6,7-dehydroferruginol, which were isolated from volatile compounds discharged from sugi wood-drying process improved disorder of motor function (paralysis) of C.elegans CL4176 caused by the $A \beta$ toxicity. Comparison of $A \beta$ toxicity reduction effect by ferruginol and the known anti-Alzheimer's disease active compounds revealed no significant difference and it was regarded that their activities were approximately same level. Furthermore, the antioxidative activity in the DPPH radical scavenging test was found only in ferruginol and 6,7-dehydroferruginol that presented $A \beta$ toxicity reduction effect, suggesting that the antioxidative activity of these compounds is the important factor to relieve the toxicity of $A \beta$. The active diterpenes revealed in this study are skin permeable and volatile, so they can be applied transdermally or nasally. In the future, it is expected to be used as a therapeutic or preventive drug for Alzheimer's disease due to the $A \beta$ toxicity reduction effect.

\section{Abbreviations}

Aß: Beta amyloid; GC: Gas chromatography; NMR: Nuclear magnetic resonance; DPPH: 1,1-Diphenyl-2-picrylhydrazyl; BHT: 2,6-Di-tert-butyl-4-methylphenol; NGM: Nematode growth medium; LB medium: Luria-Bertani medium; IC50: 50\% Inhibition concentration.

\section{Acknowledgements}

Nematode strains were provided by the Caenorhabditis Genetics Center, which is funded by the NIH Office of Research Infrastructure Programs (P40 OD010440)

\section{Authors' contributions}

YY performed isolation of diterpenoids and biological assay. TW managed C.elegans and gave advice for handling and evaluating biological assay. HK designed this study and prepared the manuscript. All authors read and approved the final manuscript.

\section{Funding}

This research was partly supported by JSPS KAKENHI Grant Number 19 K06163.

\section{Availability of data and materials}

The datasets during the current study are available from the corresponding author on reasonable request.

\section{Competing interests}

The authors declare that they have no competing interests.

\section{Author details}

1 Faculty of Agriculture, Iwate University, Ueda 3-18-8, Morioka, Iwate 020-8550, Japan. ${ }^{2}$ Faculty of Science and Engineering, Iwate University, Ueda 4-3-5, Morioka, Iwate 020-8551, Japan.

Received: 27 Auqust 2020 Accepted: 23 October 2020

Published online: 31 October 2020

References

1. The Cabinet Office (2019) White Paper on Aged Society (in Japanese), p3. https://www8.cao.go.jp/kourei/whitepaper/w-2019/zenbun/01pdf _index.html. Accessed 21 Oct 2020

2. Toshiji Ninomiya (2014) Study on estimation of population of elderly with dementia in Japan (in Japanese), Ministry of Health, Labour and Welfare Special Research, p20. https://mhlw-grants.niph.go.jp/niph/search/ NIDD00.do? resrchNum=201405037A. Accessed 21 Oct 2020

3. Hardy J, Selkoe DJ (2002) The amyloid hypothesis of Alzheimer's disease: progress and problems on the road to therapeutics. Science 297:353-356

4. Haas C, Selkoe DJ (2007) Soluble protein oligomers in neurodegeneration: lessons from the Alzheimer's amyloid $\beta$-peptide. Net Rev Mol Cell Biol 8:101-112

5. Murakami K, Irie K, Ohigashi H, Hara H, Nagao M, Shimizu T, Shirasawa $T$ (2005) Formation and stabilization model of the 42-mer Abetaradical:implications for the long-lasting oxidative stress in Alzheimer's disease. J Am Chem Soc 127:15168-15174

6. Butterfield DA (2002) Amyloid beta-peptide (1-42)-induced oxidative stress and neurotoxicity: implications for neurodegeneration in Alzheimer's Disease brain. a review. Free Radic Res 36:1307-1313

7. Tsujimura M, Goto M, Tsuji M, Yamaji Y, Ashitani T, Kimura K, Ohira T, Kofujita $\mathrm{H}$ (2019) Isolation of diterpenoids from sugi wood-drying byproducts and their bioactivities. J Wood Sci 65:19-28

8. Drake J, Link CD, Butterfield DA (2003) Oxidative stress precedes fibrillar deposition of Alzheimer's disease amyloid beta-peptide (1-42) in a transgenic Caenorhabditis elegans model. Neurobiol Aging 24:415-420

9. Yanjue Wu, Zhixin Wu, Peter B, Yves C, Mary PL, William LK, Christopher DL, Yuan L (2006) Amyloid- $\beta$-induced pathological behaviors are suppressed by Ginkgo biloba extract EGb 761 and ginkgolides in transgenic Caenorhabditis elegans. J Neuroscience 13:13102-13113

10. Ono K, Yoshiike Y, Takashima A, Hasegawa K, Naiki H, Yamada M (2006) Potent anti-amyloidogenic and fibril-destabilizing effects of polyphenols in vitro: implications for the prevention and therapeutics of Alzheimer's disease. J Neurochem 87:172-181

11. Hamaguchi T, Ono K, Murase A, Yamada M (2009) Phenolic compounds prevent Alzheimer's pathology through different effects on the amyloidbeta aggregation pathway. Am J Pathol 175:2557-2565

12. Azad N, Rassolijazi H, Jogtahaie MT, Soleimani S (2011) Neuroprotective Effects of carnosic acid in an experimental model of Alzheimer's disease in rats. Cell J 13:39-44

13. Praticò D (2008) Oxidative stress hypothesis in Alzheimer's disease: a reappraisal. Trends Pharmacol Sci 29:609-615

14. Saijo H, Kofujita H, Takahashi K, Ashitani T (2015) Antioxidant activity and mechanism of the abietane-type diterpeneferruginol. Nat Prod Res: Form Nat Prod Lett 29:1739-1743

\section{Publisher's Note}

Springer Nature remains neutral with regard to jurisdictional claims in published maps and institutional affiliations. 